\title{
Arce: despertando la Presencia: la estela del cuerpo desvaneciente y su Aura
}

\author{
Surpik Angelini
}

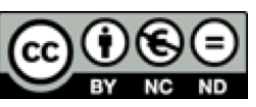

Esta obra está bajo una licencia Creative Commons

Reconocimiento-No comercial-Sin Obra Derivada 



\title{
Arce: despertando la Presencia: la estela del cuerpo desvaneciente y su Aura
}

\author{
Surpik Angelini' \\ TransArt Foundation. Houston, Texas \\ surpik@mac.com
}

Recibido: 16 de enero de 2016 Aprobado:18 de febrero de 2016

\section{Resumen}

La artista costarricense Elia Arce propone performances que evoquen una "presencia" corporal aun cuando el cuerpo ya no esté presente, remitiéndose a problemáticas que surgieron del debatido concepto del aura de Walter Benjamin. Este ensayo explorará hasta qué punto la visión de Arce instaura el aura en la obra de arte y cómo esta transforma la subjetividad singular de la visión artística en una de índole colectiva.

Palabras clave: performance, danza, arquitectura, arte, cuerpo, contemporario, experimental, aura, presencia, Walter Benjamin, Surpik Angelini, Judith Butler, Elia Arce.

\section{Abstract}

Costa Rican artist Elia Arce proposes experimental performances evoking "presence", even after the body disappears, remitting to important issues involved in Walter Benjamin's contested concept of Aura. This essay seeks to explore to what extent Arce's vision resurrects Aura in the work of art, and how it transforms singular subjectivity of artistic vision into a collective one.

Key words: performance, dance, architecture, art, body, contemporary, experimental, aura, presence, Walter Benjamin, Surpik Angelini, Judith Butler, Elia Arce.

\footnotetext{
${ }^{1}$ Surpik Angelini, architect, artist, curator, critic, founder of TransArt Foundation.
} 


\section{Artículos}

Walter Benjamin, en su famoso ensayo de 1936, "La Obra de Arte en la Era de La Reproducción Mecánica”, profetizó que en nuestro mundo actual, el arte perdería su aura. Con lo anterior, el autor quiso decir que el arte se desprendería de su presencia, autoridad, singularidad y originalidad. Curiosamente, aún después de occhenta años, la noción del aura de Benjamin todavía anima muchas discusiones académicas.

\section{Figura 1}

Cuenta larga (s.f.)
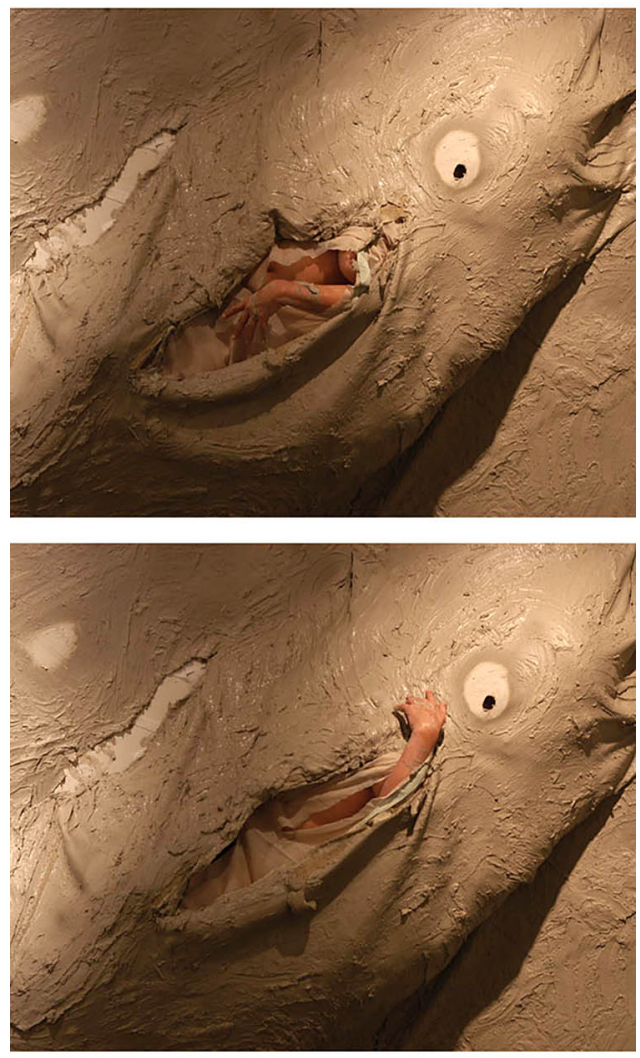

Fuente: Ben De Soto
Durante sus trabajos recientes (Album de Familia, La Cuenta Larga y Verde Claro/ Verde Oscuro), la artista costarricense Elia Arce propone performances que evoquen una "presencia" corporal aún cuando el cuerpo ya no esté presente, remitiéndose a problemáticas que surgieron del debatido concepto del aura de Benjamin. Este ensayo explorará hasta qué punto la visión de Arce instaura el aura en la obra de arte y cómo esta transforma la subjetividad singular de la visión artística en una de índole colectiva.

En un previo ensayo sobre el arte del performance, titulado "Enfrentando la memoria después de la desaparición del (cuerpo)" examiné la obra de varios artistas latinoamericanos, los cuales, en el 2002, participaron en la exposición curada por Okuwi Enwezor: Documenta XI en Kassel, Alemania. Allí, el artista Brasileño Cildo Mireilles, distribuyó al público miles de paletas de helados de agua, en las cuales se encontraba la siguiente inscripción: Elemento en desaparición/elemento desaparecido.

La obra constituyó una denuncia contra la escasez de agua a nivel global, particularmente en las cuencas del Amazonas. Recordando la cita de Judith Butler encontramos que "[...] los significantes políticos, especialmente aquellos que designan posiciones no descriptivas del sujeto, es decir, que no representan circunscripciones pre-determinadas, son signos vacíos y suelen convertirse en investimentos fantasmagóricos de varios tipos." (Butler,1993, p.191). 
Otro ejemplo que implementa la noción de la desaparición del cuerpo puede observarse en la obra memorable del artista chileno Alfredo Jaar, instalada en el 2001 con una muestra titulada Versiones del Sur: Más Allá del Documento, en el Museo Nacional Centro de Arte Reina Sofía, Madrid. La obra consiste en una enorme cantidad de cajas negras de archivos fotográficos, catalogadas meticulosamente, designando su contenido de miles de fotografías testimoniales de las víctimas del genocidio en Ruanda en 1994. Pese a las expectativas del público, las imágenes no fueron expuestas.

Esta omisión voluntaria por parte del artista convirtió la obra en una punzante alegoría de la tragedia en la que sucumbieron 800.000 personas. (Angelini, 2003). En los dos casos, Mireilles y Jaar crearon sujetos abyectos a través de la exclusión y la clausura de la figura del cuerpo, dejando solo una referencia oblicua a ella, algo que remite a Foucault cuando este declara que el cuerpo, en su forma literal, ya no ocupa el lugar del poder político y social.

En sus recientes experimentos con estudiantes, Elia Arce propone un acercamiento diferente al tema de la desaparición del cuerpo. Ya no se trata de una operación conceptual, simbólica o alegórica, como en la obra de Jaar y Mireilles, donde se alude a eventos políticos. Arce explora la posibilidad de crear presencia aún cuando el cuerpo deja de estar presente. A diferencia de Jaar y Mireilles, ella busca una "presencia" que trascienda las huellas temporales de un performance precedente o la articulación temporal de un evento histórico.

Desde su punto de vista, Arce sostiene el potencial de despertar una "presencia" en las cosas incluyendo, sobre todo, los objetos comunes y no solo los objetos de arte. Esta noción del aura se acerca a la definición que hace Benjamin. Es un hecho fundamental, ya que en nuestro mundo contemporáneo, después de la introducción del "objeto encontrado" de Duchamp, estamos acostumbrados a la idea de que cualquier objeto puede ser elevado a la categoría de arte con una simple designación. Es de notar aquí que, a diferencia de la propuesta de Arce, en la representación de objetos cotidianos por artistas del movimiento Pop, como Andy Warhol, Jasper Johns, Caty Noland, y tantos otros, se nota la ausencia del aura en el objeto de arte, tal como fue anunciado por Benjamin.

Para su campo de experimentación, Arce escoge dos casas en San José de Costa Rica, con todos sus componentes espaciales y arquitectónicos (paredes, escaleras, muebles, objetos), las cuales serán el foco central de las intervenciones performáticas delos estudiantes. De tal modo, el ejercicio propuesto consistirá en intervenir un elemento existente de la casa. No se tratará de reconstruir nostálgicamente su historia particular, ni tampoco se tratará de ilustrar un concepto abstracto o una narrativa personal. En cambio, se buscará eliminar cualquier noción de tiempo, tratando el tiempo como una ruina sobre la cual se construye una imagen que transcienda la temporalidad. La obra se generará a través de 


\section{Artículos}

la interacción entre el cuerpo arquitectónico y el cuerpo del artista del performance.

En esta coyuntura, me debo remitir a otro aspecto del aura descrito por Benjamin en sus Arcadas, donde habla de

[...] la habilidad [del aura] de devolvernos la mirada. Aura se entiende aquí como un extraño entretejido enlazando el espacio y el tiempo: la aparición, (o semblanza) de una distancia, por más cercana que esté (o por más cercana que esté la cosa que la emite): de modo que también el aura se entiende como una forma de percepción que le otorga al fenómeno la habilidad de devolvernos la mirada, de abrir los ojos o de levantar la propia mirada. (Benjamin, 1999, p.324)

Es interesante notar que, como consecuencia de un intercambio intersubjetivo entre el cuerpo inerte arquitectónico y el cuerpo vivo del artista del performance, la mirada del sujeto y del objeto se vuelven intercambiables. De modo que, cuando el objeto inerte le devuelve la mirada al artista, el objeto -ahora visto con extrañamiento y distancia- parece estar investido con una presencia atemporal. Debo añadir que tanto las cosas animadas como las inertes entran en la misma categoría de "cosas investidas con presencia", de modo que un cuerpo vivo extendido sobre una piedra, como resultado de una acción performática, también puede ser visto como "una cosa inerte investida con presencia”.

En el capítulo "El flâneur" de Las Arcadas,
Benjamin usa ideas similares a las citadas anteriormente, introduciendo el concepto de huella y su relación con el aura:

Huella y aura. La huella es una apariencia de cercanía, a pesar de lo lejos que esté la cosa que dejamos atrás. El aura, en cambio, es la apariencia de lejanía, sin importar lo cercano que esté la cosa que la emite. Con la huella, nos apoderamos de la cosa; con el aura, la cosa se apodera de nosotros. (Benjamin, 1999, p.446)

En este sentido, Arce instruye a sus estudiantes a entrar en la casa con una actitud totalmente desfamiliarizada en cuanto a la percepción de esa nueva realidad, la cual debe ser observada como si ellos fueran visitantes de otro mundo. La práctica de la desfamiliarización fue adoptada por los surrealistas desde los albores del siglo XX, cuando sondeaban el "inconsciente". Posteriormente, se convirtió en la actitud indisputada de los antropólogos posmodernos en su intento de percibir el Otro evitando ideas preconcebidas, inherentes a su propia cultura.

Pertinente al caso, contamos con dos ejemplos que surgieron de los experimentos de Arce con los estudiantes en La Casa de Peke o Casa Mágica. El primero fue concebido por Ana Lucía Rodríguez, quien intervino las grietas de las paredes y el techo de la casa con curitas durante el transcurso de la noche. El otro ejemplo, dispone el cuerpo de la artista Sofía Solís, vestida de buzo, a lo largo de un espejo de agua vacío, que ella llenó de bolsas de plástico y agua. El espejo de agua está ubicado en un espacio muy reducido 
entre un ventanal y la escalera en el interior de la casa, en el cual su cuerpo calzaba a lo largo y a lo ancho perfectamente.

Con ambos ejemplos, observamos que la narrativa asociada con la casa ha sido suprimida por la presencia del Otro, o sea, con la intervención corporal del artista, que ejecuta una acción o un performance, que puede ser visible o invisible. Como consecuencia,

\section{Figura 2}

Ana Lucía Rodríguez, La Casa de Peke o Casa Mágica, (s.f.)

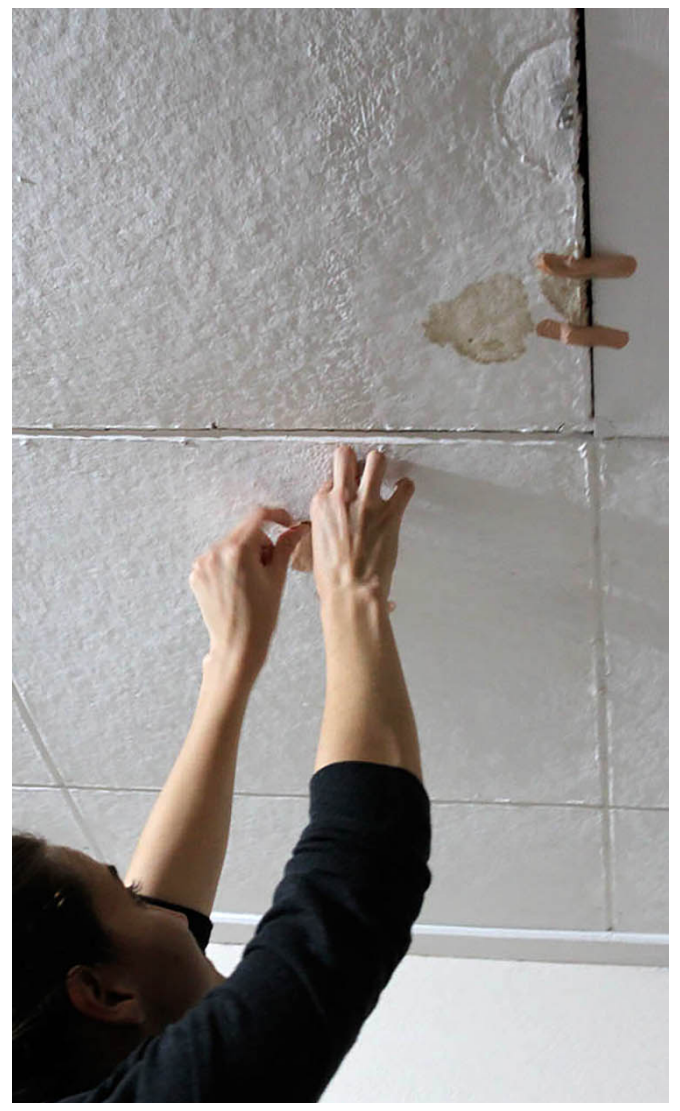

Fuente: Elia Arce las dos narrativas -la del artista y la de la casa- se cancelan mutuamente, en vista de que el público carece de un contexto para reconstruir sus historias. Sin embargo, ambas presencias sobreviven con una sugestiva aura que se percibe como parte del acto creador del objeto de arte, el cual, ya no referido a la subjetividad individual del artista se convierte sorpresivamente en un fenómeno colectivo.

\section{Figura 3}

Sof ía Solís, La Casa de Peke o Casa Mágica, (s.f.)

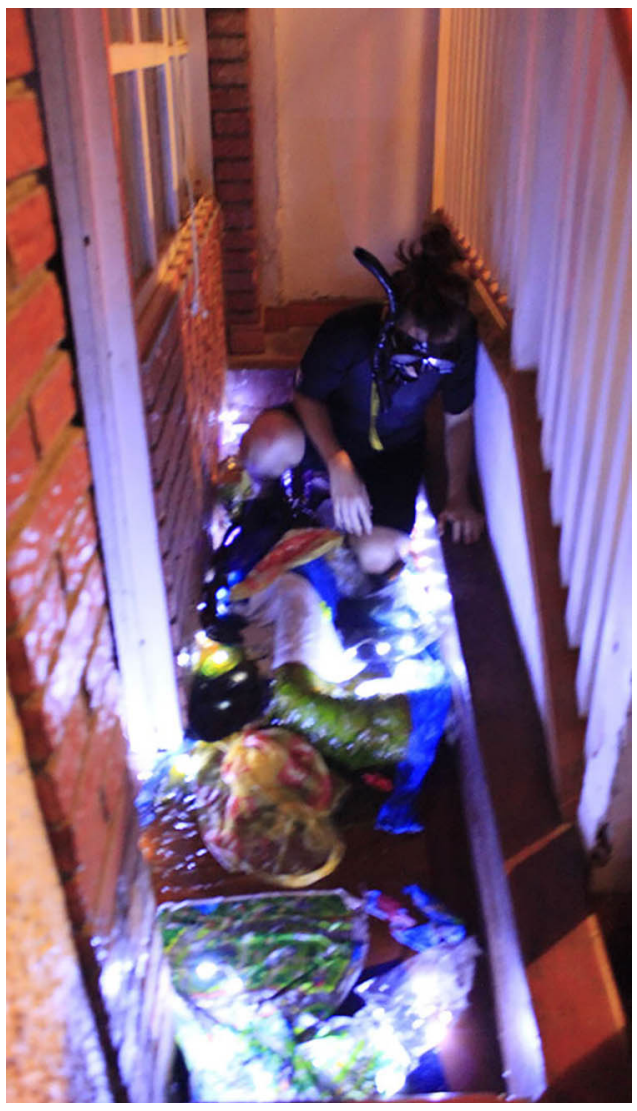

Fuente: Elia Arce 


\section{Artículos}

Hemos llegado a un punto en el que podríamos divagar del concepto singular del aura sostenido por Benjamin. Con mucha razón este autor vio la desaparición del aura en el arte, cuando se basó en su acepción tradicional burguesa, que implica el culto fetichista de la originalidad y la autoría singular de la obra de arte. En este sentido, los medios modernos de reproducción masiva, como la fotografía y el cine, ciertamente destruyeron el aura de la obra de arte. Sin embargo, Arce solo señala la presencia del aura en imágenes oníricas colectivas. Ella comparte el interés de Benjamin en explorar el sueño colectivo surgido del repentino destello de la memoria involuntaria o, como diría el autor, a través de la mirada desfamiliarizada del flâneur.

Arce les indica a sus estudiantes que deben "olvidar la historia" cuando exploren estas casas. Así mismo, en Las Arcadas de París, Benjamin comenta la experiencia del flâneur, quien "[...] se desplaza por las arcadas como en un sueño. La existencia en estos espacios fluye sin altibajos, como los eventos en un sueño. Flanerie es el ritmo de este sopor". (1999, p. 881). Asimismo, Benjamin declara:

El nuevo método dialéctico para hacer historia nos enseña a pasearnos como espíritus- con la rapidez y la intensidad de un sueño, atravesando lo acontecido de manera de experimentar el presente como el despertar de un mundo, un mundo al cual ultimadamente se refiere todo sueño. (1999, p.884)

Con esta visión, explica el autor,
[...] la mirada del objeto, por más familiar que sea, es experimentada por el sujeto como si fuera Otra precedente, extraña y heterónoma. Conceptualizada en términos de una carencia, un quiebre, una pérdida, esta otra mirada, a su vez, confronta al sujeto con un extrañamiento fundamental, intrínseco y adentro de sí. (Benjamin, 1999, p. 884)

Figura 1

Manuel Fernández, La Casa de Peke o Casa Mágica, (s.f.)

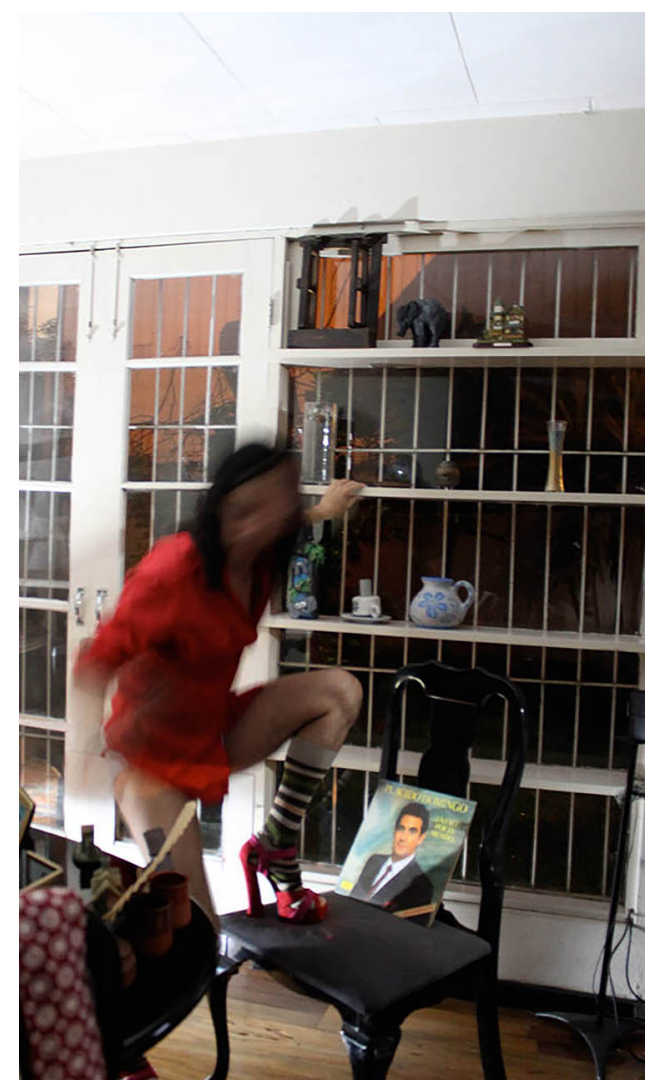

Fuente: Elia Arce 
Para Benjamin, la forma renovada de ver la historia comenzaría coleccionando cosas, lo cual, para él, constituiría la esencia de la memoria práctica. Dice Benjamin, que coleccionar es una forma incipiente del acto de recordar, el cual se encuentra en una oposición dialéctica con el despertar (de la conciencia). Viene al caso otro experimento pertinente, cuando el estudiante se encuentra ante una colección de un centenar de figuritas dispuestas a contraluz en una ventana de la casa. La acción de su performance, consiste en tomar cada figurita, limpiarla meticulosamente (de su historia pasada) y luego ponerlas sobre la mesa del comedor. Una vez dispuestas todas las figuritas en la mesa, el artista Manuel Fernández las devuelve a su estante en la ventana. Con esta simple acción, el artista pretende detenerse ante el recuerdo que evoca cada figurita, y al limpiar cada una, parece borrar sus memorias singulares. Finalmente, cuando las devuelve a su lugar, provoca una abrupta sensación de despertar, la cual se transforma en una experiencia colectiva compartida.

Cuando visitamos La Casa de Peke o Casa Mágica intervenida por los estudiantes, sus sueños se confunden con los nuestros, evocando nuestras propias memorias involuntarias, como las llamó Proust, y así, nos convertimos en voyeurs de una experiencia colectiva. Con estos sencillos ejercicios, podemos apreciar las condiciones establecidas conceptualmente por Elia Arce, no solo para infundir presencia, o aura, a los cuerpos vivos e inertes, pero también observamos, con claridad, cómo el acto de reprimir el aspecto temporal de la narrativa particular del objeto y el sujeto, convierte la experiencia del performance en algo transcendente y de naturaleza colectiva.

Este es un ejercicio iluminador, con pocos precedentes, que delimita y condiciona un proceso creativo capaz de sondear la memoria involuntaria o el "inconsciente" personal del artista para transformarse en una experiencia misteriosa y elusiva dotada con el aura de la obra de arte.

\section{Referencias}

Angelini, S. (2003). Facing Memory after the disappearance of (The Body). Revista Gestos, Teoría y Practica del Teatro Hispano. University of California, California, 18(36): 27-42.

Benjamin, W. (1968). The Work of Art in the Age of Mechanical Reproduction, Illuminations. London: Fontana: 214-218.

Benjamin, W. (1999). Arcades Project. The Bellknap Press of Harvard University Press: Cambridge and London.

Hansen, M. (2008). Benjamin's Aura. Critical Inquiry 34: 336-375. University of Chicago. 